\title{
Theoretical Research on the Mechanism of the Dimerization Reactions of Alkyl Ketene
}

\author{
Zhiguo Zhang, Guoneng Li, Guilin Hu, and Yaoyu Sun \\ School of Light Industry, Zhejiang University of Science and Technology, Liuhe Road No. 318, Hangzhou, Zhejiang 310023, China \\ Correspondence should be addressed to Zhiguo Zhang; 107023@zust.edu.cn
}

Received 30 May 2013; Accepted 16 August 2013

Academic Editor: David L. Cedeno

Copyright (c) 2013 Zhiguo Zhang et al. This is an open access article distributed under the Creative Commons Attribution License, which permits unrestricted use, distribution, and reproduction in any medium, provided the original work is properly cited.

\begin{abstract}
A quantum chemical method was employed to investigate the mechanism of dimerization reactions of alkyl ketene. All the geometric configurations of the stationary points on the reactions path were optimized with Gaussian03 employing density functional theory at the B3LYP/6-311G++ $(\mathrm{d}, \mathrm{p})$ level by energy gradient technique. The transition states were also investigated through synchronous transit method, and its reasonability was confirmed by using frequency analysis and intrinsic reaction coordinate analysis. The results can be summed up as follows: according to the frontier orbital theory, the dimerization reaction (3) to generate four-membered carbon cyclic product P3 is forbidden. Two different dimerization processes of alkyl ketene are all concerted but nonsynchronous, taking place through twisted four-membered cyclic transition states. The activation energies were calculated to be 34.54 and $61.73 \mathrm{~kJ} / \mathrm{mol}$, respectively for the two ketene dimerization processes. Calculation results satisfactorily explained the experimental facts.
\end{abstract}

\section{Introduction}

Alkyl ketene dimer (AKD) also called AKD wax and alkenyl Succinic Anhydride (ASA) are wax like chemicals. AKD (alkyl ketene dimers, I) is an excellent neutral sizing agent and is widely used in the paper making industry [1-3]. Traditionally rosin (acidic sizing) was used as a paper sizing material. Due to changes in paper manufacturing technologies, the sizing process is changed to alkaline/neutral sizing from acidic sizing. AKD and ASA are the main neutral sizing chemicals. In both cases the aim is to retain hydrophobic molecules in the sheet of the paper [4]. AKD/ASA is used in the form of emulsions (10\% AKD/ASA) in sizing of finer qualities of paper. Compared to acidic sizing agent (Gum Rosin), the neutral/alkaline sizing agent (AKD) is a chemical treatment that reduces machine breakdown and water recycling difficulties of the standard acidic paper manufacture process by minimizing water absorption and enhancing the surface conditions of paper during a neutral paper manufacturing process. The new neutral and alkaline sizing techniques have been found to be more efficient owing to their better hydrophobicity and smaller size reversion. $\mathrm{AKD}$ is less susceptible to hydrolysis but is also less reactive towards the cellulose fibers and usually requires considerable time (weeks) to develop a satisfactory sizing effect $[5,6]$. AKD plays a significant role in minimizing the detrimental environmental impact of water contamination by facilitating the recycling of water in the paper production process [7-9].

The demand for the emulsions is estimated at 30000 tons per year and the demand for AKD/ASA at about 3000 tons. Alkyl ketene dimers are produced by reacting a $\mathrm{C}_{8}-$ $\mathrm{C}_{22}$ saturated or unsaturated linear fatty acid chloride with a cyclic tertiary amine in an inert solvent at a temperature of up to $75^{\circ} \mathrm{C}$, separating tertiary amine hydrochloride salts from the alkyl ketene dimer in the solvent, and recovering the alkyl ketene dimer by distillation from the solvent. China is a huge paper maker, with paper and paper board output totaling 50 million MT in 2005 and is estimated to reach 100 million MT by 2015 . In an effort to upgrade the quality and grade of paper, the application of neutral sizing agents will be promoted. In this regard, AKD will be in great demand [10-12].

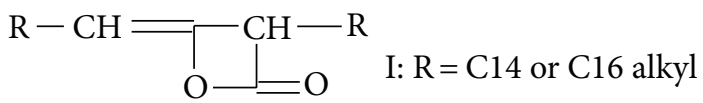


Alkyl ketene dimers can be prepared by reaction of acid halides with tertiary amines in inert organic solvents, and the main reaction is the dimerization reaction of alkyl ketene [11]. It is generally believed that the reaction pathway involves, first of all, a reaction between acid halides and triethylamine to form a monoalkyl ketene intermediate:

$$
\begin{gathered}
\mathrm{RCH}_{2}-\stackrel{\mathrm{O}}{\mathrm{C}}-\mathrm{Cl}+\left(\mathrm{C}_{2} \mathrm{H}_{5}\right)_{3} \mathrm{~N} \longrightarrow \\
\mathrm{R}-\mathrm{CH}=\mathrm{C}=\mathrm{O}+\left(\mathrm{C}_{2} \mathrm{H}_{5}\right)_{3} \mathrm{~N} \cdot \mathrm{HCl}
\end{gathered}
$$

Then, the alkyl ketene dimerization reaction occurs quickly producing AKD products:

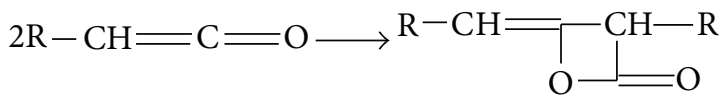

In the dimerization reaction, alkyl ketene always forms four-ring compounds. It is of significant importance to research the cycloaddition reaction mechanism of alkyl ketene for the synthesis of AKD and the rich chemical theories.

To the best of our knowledge, the investigations of dimerization reactions of alkyl ketene are mainly focused on experimental study and rarely on theoretical study $[13,14]$. In this paper, the quantum chemical method was employed to investigate the mechanism of dimerization reactions of alkyl ketene.

Quantum chemistry is based on the postulates of quantum mechanics. In quantum chemistry, the system is described by a wave function which can be found by solving the Schrödinger equation. This equation relates the stationary states of the system and their energies to the Hamiltonian operator, which can be viewed as the recipe for obtaining the energy associated with a wavefunction describing the positions of the nuclei and electrons in the system. Now, quantum chemical methods are widely used in many important questions in chemistry that cannot at all be addressed by means of the empirical approach [15].

Three possible dimerization reactions of alkyl ketene were investigated in this paper. The reaction mechanism was studied by using quantum chemical calculations to explain the observed regioselectivity. Without loss of generality, ethyl is chosen as the alkyl group for the convenience of calculation:

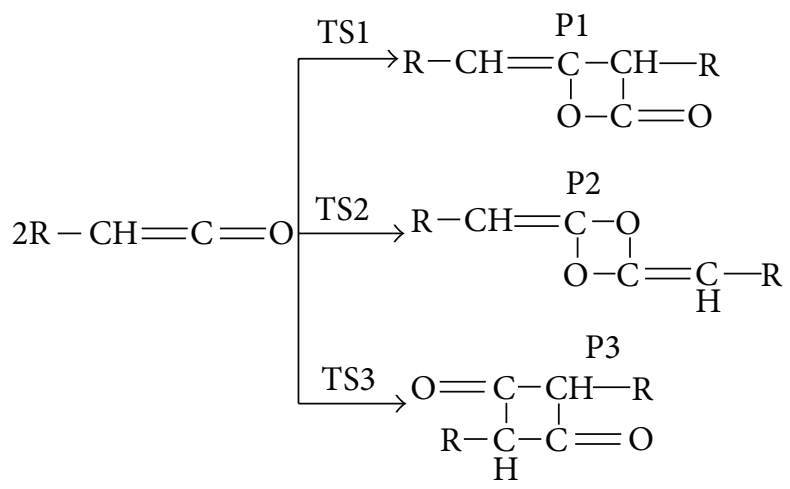

\section{Methods and Computations}

The previous modeling molecules above were employed for the optimizations of the structures of the reaction species at the B3LYP/6-311G++(d, p) level with Gaussian03 [16]. The frontier orbital of the reactant ethyl ketene is calculated to illustrate the reaction mechanism. The vibrational analysis for all the optimized structures is performed at the same computational level to obtain reliable vibrational frequencies, zero-point energy, and total energy. All the intermediates and transition states are confirmed by the results of vibration analysis and intrinsic reaction coordinate (IRC) calculation.

\section{Results and Discussion}

3.1. Frontier Orbital. The dimerization reaction of ketene is a kind of cycloaddition reaction, which is generally concerted and has the cyclic transition state to complete the fracture and generation of the molecular bond. The reactions follow the principle of molecular orbital symmetry conservation. The frontier orbital of alkyl ketene is calculated and is shown in Figure 1.

The highest-energy occupied molecular orbital (HOMO) and the lowest-energy unoccupied molecular orbital (LUMO) of alkyl ketene have substantially different electronic distributions. The next LUMO (LUMO-1) has the orbital energy very close to the LUMO orbital energy, and its electronic distribution is also shown in Figure 1.

When two independent molecules react, frontier orbital theory requires us to select the HOMO of one molecule and the LUMO of the other to interact, so that electron flow can occur from one molecule (the HOMO) to the other (the LUMO).

As shown in Figure 1, the HOMO of one molecule of alkyl ketene and the LUMO of the other could overlap in phase. This choice results in the reaction (2) being allowed. In this situation, the $\mathrm{C}=\mathrm{O}$ bond in the HOMO of one molecule of alkyl ketene could react with the other $\mathrm{C}=\mathrm{O}$ bond in the LUMO of the other molecule to produce the product P2. Similarly, the HOMO of one molecule of alkyl ketene and the LUMO-1 of the other could overlap in phase, and this results in the reaction (1) being allowed. In this situation, the $\mathrm{C}=\mathrm{O}$ bond in the HOMO of one molecule of alkyl ketene could react with the other $\mathrm{C}=\mathrm{C}$ bond in the LUMO- 1 of the other molecule to produce the product $\mathrm{P} 1$ (AKD). But the $\mathrm{C}=\mathrm{C}$ bond in the HOMO of one molecule of alkyl ketene cannot react with the other $\mathrm{C}=\mathrm{C}$ bond of the other molecule to produce the product $\mathrm{P} 3$. The different phase results in the reaction (3) being forbidden.

3.2. Dimerization Reaction of Ketene. All the geometric configurations of the stationary points on the reactions path were optimized with Gaussian03 in density functional theory at B3LYP/6-311G++(d, p) level by the energy gradient technique. And all the transition states were also investigated through the synchronous transit method. In the calculation of the dimerization reactions (1) and (2) of alkyl ketene, the optimized structures of reactant and two transition states 


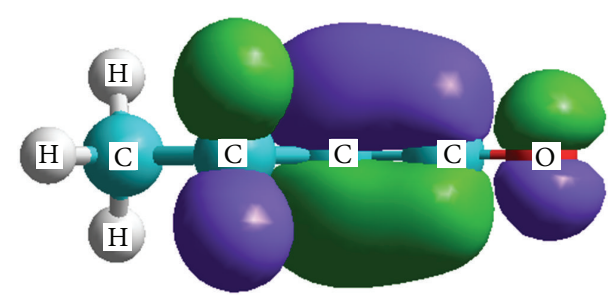

(a)

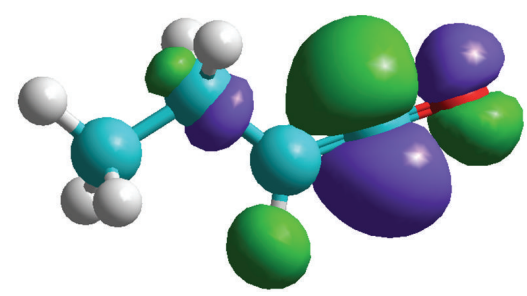

(b)

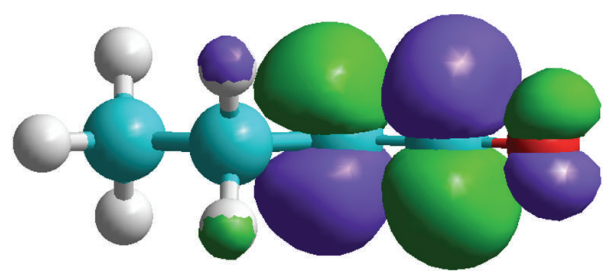

(c)

FigURE 1: Frontier orbital of alkyl ketene. (a) HOMO; (b) LUMO; (c) LUMO-1.

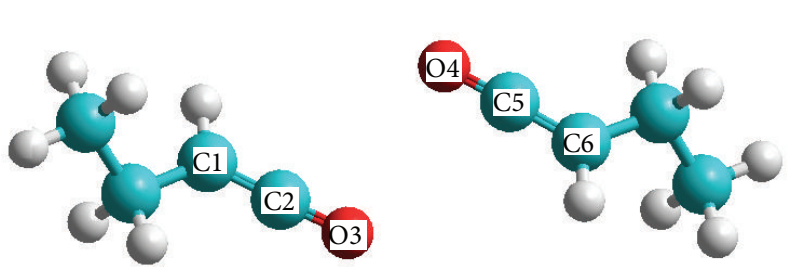

(a)

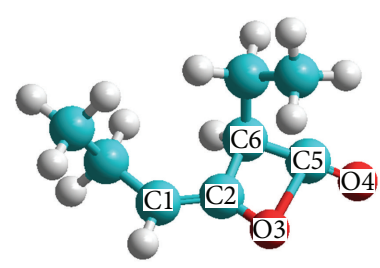

(b)

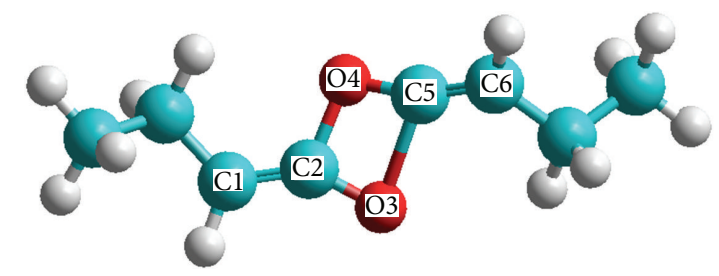

(c)

FIGURE 2: The optimized structures of reactant (a) and transition states ((b): TS1; (c): TS2).

are shown in Figure 2, in which the two transition states represent two different pathways (reactions (1) and (2)).

By means of the vibrational analysis on stationary points, it is clear that vibrational frequencies of the reactants and the products are all positive and stationary points are stable. The calculated result of the vibrational analysis shows that there is only one strong imaginary frequency in the transition states, and the imaginary frequency of TS1(B) is $-338.65 \mathrm{i}$ and the imaginary frequency of TS2(C) is -886.18 . The vibration vector direction of corresponding imaginary frequency represents the fracture and generation of the molecular bond to construct the four-membered cyclic transition states. The two transition states are verified by the intrinsic reaction coordinate (IRC) analysis.

The main geometric parameters for transition states (TS1 and TS2) and products (P1 and P2) of the dimerization reaction of alkyl ketene are listed in Table 1 by using quantum chemical method. As shown in Table 1, the products P1 (AKD) and P2 have the plane four-membered cyclic molecular skeleton, while the corresponding transition states TS1 and TS2 have the twisted four-membered cyclic molecular skeleton.

In the reaction (1), the $\mathrm{C}=\mathrm{O}$ bond in the $\mathrm{HOMO}$ of one molecule of alkyl ketene could react with the other $\mathrm{C}=\mathrm{C}$ bond in the LUMO-1 of the other molecule to produce the product $\mathrm{P} 1$ (AKD). The $\mathrm{C} 2-\mathrm{C} 6$ bond and $\mathrm{C} 5-\mathrm{O} 3$ bond are the new generation molecular bonds to construct the four-membered ring. As shown in Table 1, the C2-C6 bond length is $0.1593 \mathrm{~nm}$ in the TS1 and $0.1522 \mathrm{~nm}$ in the P1. This shows that the C2-C6 bond has been formed in the transition state TS1. While the C5-O3 bond length is $0.2347 \mathrm{~nm}$ in the TS1 and $0.1414 \mathrm{~nm}$ in the $\mathrm{P} 1$, this shows that the $\mathrm{C} 5-\mathrm{O} 3$ bond is not formed in the transition state TS1. Therefore, the two new bond formations are not synchronous in the reaction pathway. In addition, the $\angle \mathrm{C} 2 \mathrm{O} 3 \mathrm{C} 5 \mathrm{C} 6$ is $12.3^{\circ}$ in the transition state TS1, and this shows that TS1 has the twisted four-membered cyclic molecular skeleton. The transition state TS1 is verified by the intrinsic reaction coordinate (IRC) analysis; that is, TS1 connects directly the reactant and product P1 (AKD) in the reaction path (1), and this shows that the two new bonds 
TABLE 1: The main geometric parameters for transition states (TS1 and TS2) and products (P1 and P2) of dimerization reaction of alkyl ketene (bond length: $\mathrm{nm}$; bond angle: deg.).

\begin{tabular}{lcccc}
\hline Reaction & \multicolumn{4}{c}{ Bond length } \\
\hline$(1)$ & $\mathrm{C} 2-\mathrm{O} 3$ & $\mathrm{C} 2-\mathrm{C} 6$ & $\mathrm{C} 5-\mathrm{O} 3$ & $\mathrm{C} 5-\mathrm{C} 6$ \\
TS1 & 0.1278 & 0.1593 & 0.2347 & 0.1447 \\
P1 & 0.1431 & 0.1522 & 0.1414 & 0.1535 \\
$(2)$ & $\mathrm{C} 2-\mathrm{O} 3$ & $\mathrm{C} 2-\mathrm{O} 4$ & $\mathrm{C} 5-\mathrm{O} 3$ & $\mathrm{C} 5-\mathrm{O} 4$ \\
TS2 & 0.1303 & 0.1530 & 0.1949 & 0.1296 \\
P2 & 0.1419 & 0.1419 & 0.1419 & 0.1419 \\
\hline Reaction & \multicolumn{5}{c}{ Bond angle } \\
\hline$(1)$ & $\angle \mathrm{C} 1 \mathrm{C} 2 \mathrm{O} 3$ & $\angle \mathrm{C} 6 \mathrm{C} 2 \mathrm{O} 3$ & $\angle \mathrm{C} 2 \mathrm{O} 3 \mathrm{C} 5$ & $\angle \mathrm{C} 2 \mathrm{O} 3 \mathrm{C} 5 \mathrm{C} 6$ \\
TS1 & 132.29 & 109.65 & 74.27 & 12.30 \\
P1 & 125.28 & 93.02 & 90.80 & 0.65 \\
$(2)$ & $\angle \mathrm{C} 1 \mathrm{C} 2 \mathrm{O} 3$ & $\angle \mathrm{O} 4 \mathrm{C} 2 \mathrm{O} 3$ & $\angle \mathrm{C} 2 \mathrm{O} 3 \mathrm{C} 5$ & $\angle \mathrm{C} 2 \mathrm{O} 3 \mathrm{C} 5 \mathrm{O} 4$ \\
TS2 & 143.57 & 95.69 & 81.14 & -17.30 \\
P2 & 133.02 & 92.45 & 87.55 & 0.05 \\
\hline
\end{tabular}

are not formed at the same time but the process is still one elementary step.

In the reaction (2), the $\mathrm{C}=\mathrm{O}$ bond in the HOMO of one molecule of alkyl ketene could react with the other $\mathrm{C}=\mathrm{O}$ bond in the LUMO of the other molecule to produce the product $\mathrm{P} 2$. The $\mathrm{C} 2-\mathrm{O} 4$ bond and $\mathrm{C} 5-\mathrm{O} 3$ bond are the new generation molecular bonds to construct the four-membered ring. As shown in Table 1, the $\mathrm{C} 2-\mathrm{O} 4$ bond length is $0.1530 \mathrm{~nm}$ in the TS2 and $0.1419 \mathrm{~nm}$ in the P2. This shows that the $\mathrm{C} 2-\mathrm{O} 4$ bond has been formed in the transition state TS2. While the C5-O3 bond length is $0.1949 \mathrm{~nm}$ in the TS2 and $0.1419 \mathrm{~nm}$ in the $\mathrm{P} 2$, this shows that the $\mathrm{C} 5-\mathrm{O} 3$ bond is not formed yet in the transition state TS2. Therefore, the two new bond formations are not synchronous in the reaction pathway. In addition, the $\angle \mathrm{C} 2 \mathrm{O} 3 \mathrm{C} 5 \mathrm{O} 4$ is $-17.3^{\circ}$ in the transition state TS2, and this shows that TS2 has the twisted four-membered cyclic molecular skeleton. The transition state TS2 is verified by the intrinsic reaction coordinate (IRC) analysis; that is, TS2 connects directly the reactant and product $\mathrm{P} 2$ in the reaction path (2), and this shows that the two new bonds are not formed at the same time but the process is still one elementary step.

Two transition states TS1 and TS2 are the asymmetric four-ring structure, which showed that the two different dimerization processes of alkyl ketene are all concerted but nonsynchronous, taking place through twisted four-membered cyclic transition states. The reaction pathway includes only a one-step elementary reaction process, but two new bond formations are not synchronous.

Using theoretical calculations, the total energies and zeropoint energies of the different reaction species and both reaction activation energies corrected with zero-point vibrational energies are obtained. The potential energy surfaces of two different dimerization processes of alkyl ketene were shown in Figure 3. From the thermodynamic point of view, product $\mathrm{P} 1$ (AKD) is more stable than product $\mathrm{P} 2$, because product P1 (AKD) potential energy surface is lower than product P2 potential energy surface.

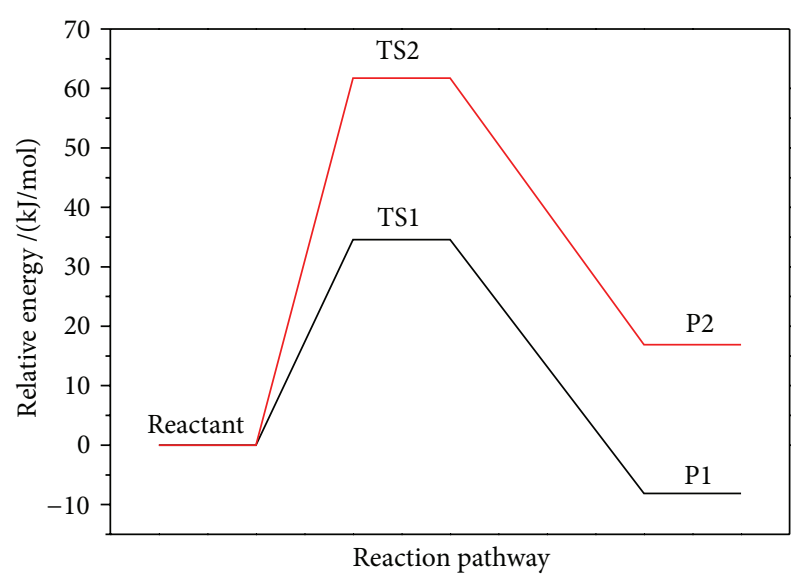

Figure 3: Potential energy surfaces of two different dimerization processes of alkyl ketene.

The activation energies were calculated to be 34.54 and $61.73 \mathrm{~kJ} / \mathrm{mol}$, respectively, for the two alkyl ketene dimerization processes: reactions (1) and (2). Apparently, the two reactions shown above are parallel reactions. The activation energy of reaction pathway (1), which produces the AKD (P1) products, was much lower than the other reaction pathway (2). According to transition state theory and kinetics of parallel reaction [17], reaction pathway (1) is the dominant process with high regioselectivity. There are

$$
\begin{aligned}
& k_{\mathrm{TS} 1}=\frac{k T}{h} \exp \left(\frac{-\Delta G_{\mathrm{TS} 1}^{\neq}}{R T}\right), \\
& k_{\mathrm{TS} 2}=\frac{k T}{h} \exp \left(\frac{-\Delta G_{\mathrm{TS} 2}^{\neq}}{R T}\right) .
\end{aligned}
$$

And then,

$$
\frac{P_{\mathrm{TS} 1}}{P_{\mathrm{TS} 2}}=\frac{k_{\mathrm{TS} 1}}{k_{\mathrm{TS} 2}}=\exp \left(\frac{\Delta G_{\mathrm{TS} 2}^{\neq}-\Delta G_{\mathrm{TS} 1}^{\neq}}{R T}\right)=\exp \left(\frac{\Delta \Delta G^{\neq}}{R T}\right) .
$$

In the parallel reaction of alkyl ketene dimerization process, the difference between the two activation energies is $61.73-34.54=27.19 \mathrm{~kJ} / \mathrm{mol}$; suppose $T=348.15 \mathrm{~K}$; then

$$
\frac{P_{\mathrm{TS} 1}}{P_{\mathrm{TS} 2}}=\exp \left(\frac{27.19 \times 1000}{8.314 \times 348.15}\right)=12011.45 .
$$

The selectivity of the reaction is as high as $99.99 \%$. Therefore, the dimerization reaction is under the dynamics control, and the main product is AKD products (P1), which is in satisfactory agreement with the experimental facts. References on experimental dimerization reaction of the alkyl ketene has been revealed only to find the product P1 (AKD), while the product $\mathrm{P} 2$ has not been reported [18-20]. The theoretical analysis coincides with experimental results very well. 


\section{Conclusion}

(1) According to the frontier orbital theory, reactions (1) and (2) are allowed, while reaction (3) is forbidden.

(2) Two different dimerization processes of alkyl ketene (reactions (1) and (2)) are both concerted but nonsynchronous, taking place through twisted fourmembered cyclic transition states.

(3) The activation energies were calculated to be 34.54 and $61.73 \mathrm{~kJ} / \mathrm{mol}$, respectively, for the two alkyl ketene dimerization processes: reactions (1) and (2). The agreement of the theoretical study with the experimental results indicates that the application of quantum chemical method in dimerization reaction of alkyl ketene is feasible.

\section{Acknowledgments}

This work was financially supported by the National Natural Science Foundation of China (51206148, 51106140) and Zhejiang Provinical Natural Science Foundation of China (Y1110642, Y407311).

\section{References}

[1] K. Mohlin, P. Karlsson, and K. Holmberg, "Use of cleavable surfactants for alkyl ketene dimer (AKD) dispersions," Colloids and Surfaces A, vol. 274, no. 1-3, pp. 200-210, 2006.

[2] K. Mohlina, N. Lorénb, and M. Nydén, "Water pores in alkyl ketene dimer (AKD) dispersions studied by NMR diffusometry and optical microscopy," Colloids and Surfaces A, vol. 297, no. 1-3, pp. 114-121, 2007.

[3] Y. S. Chew, H. Xiao, G. Peng, J. C. Roberts, K. Nurmi, and K. Sundberg, "Characteristics of AKD emulsion prepared by cationic starch with well-defined structures," Journal of Tianjin University of Science \& Technology, vol. 19, no. 21, p. 331, 2004.

[4] S. Kumar, V. S. Chauhan, and S. K. Chakrabarti, "Chakrabarti. Separation and analysis techniques for bound and unbound alkyl ketene dimer (AKD) in paper: a review," Arabian Journal of Chemistry, vol. 23, pp. 1-7, 2012.

[5] B. H. Hutton and I. H. Parker, "A surface study of cellulose fibres impregnated with alkyl ketene dimers via subcritical and supercritical carbon dioxide," Colloids and Surfaces A, vol. 334, no. 1-3, pp. 59-65, 2009.

[6] A. V. Shchukarev, R. Mattsson, and L. Ödberg, "XPS imaging of surface diffusion of alkylketene dimer on paper surfaces," Colloids and Surfaces A, vol. 219, no. 1-3, pp. 35-43, 2003.

[7] J. Tian, L. Wang, M. Hudry-Clergeon, and W. Shen, "An experimental method for measuring the spreading velocity of surface active substances on thin films of liquid substrate," Chemical Engineering Science, vol. 64, no. 14, pp. 3311-3319, 2009.

[8] C. Quan, O. Werner, L. Wågberg, and C. Turner, "Generation of superhydrophobic paper surfaces by a rapidly expanding supercritical carbon dioxide-alkyl ketene dimer solution," The Journal of Supercritical Fluids, vol. 49, no. 1, pp. 117-124, 2009.

[9] O. Werner and C. Turner, "Investigation of different particle sizes on superhydrophobic surfaces made by rapid expansion of supercritical solution with in situ laser diffraction (RESS-LD," The Journal of Supercritical Fluids, vol. 67, pp. 53-59, 2012.
[10] H. Liu and W. Liu, "The synthesis and application in papermaking of AKD," Shanghai Paper Making, vol. 38, no. 2, p. 36, 2007.

[11] J. Li and G. Fu, "Inquiring into AKD neutral sizing," Paper Chemicals, vol. 19, no. 1, p. 29, 2007.

[12] Z. Han, "Synthesis of neutral sizing agent hexadecyl ketene dimer," Chemical Techno-Economics, vol. 23, no. 5, p. 29, 2005.

[13] X. Song, F. Chen, S. Wang, F. Liu, H. Wu, and H. Xu, "Calculation reactivity of alkyl ketene dimer with ethanol and characterization of reaction products," Acta Chimica Sinica, vol. 69, no. 23, pp. 2796-2800, 2011.

[14] H. Zhang, D. Kannangara, M. Hilder, R. Ettl, and W. Shen, "The role of vapour deposition in the hydrophobization treatment of cellulose fibres using alkyl ketene dimers and alkenyl succinic acid anhydrides," Colloids and Surfaces A, vol. 297, no. 1-3, pp. 203-210, 2007.

[15] Szabo and Ostlund, Modern Quantum Chemistry, McGrawHill, 1989.

[16] M. J. Frisch, G. W. Trucks, H. B. Schlegel et al., Gaussian 03, Revision B.03, Gaussian, Pittsburgh, Pa, USA, 2003.

[17] Y. Wei and J. Li, An Introduction to Chemical Reaction Mechanisms, Edited by Y. Wei, J. Li, Science Press, 2004.

[18] B. Feng, X. Yang, and J. Li, "Optimal synthesis of neutral sizing agent," Journal of Qingdao Institute of Chemical Technology, vol. 18 , no. 3, pp. 238-240, 1997.

[19] J. Wang and W. Liu, "A review of alkyl ketene dimmer sizing," Paper and Paper Making, vol. 30, no. 3, pp. 47-50, 2011.

[20] W. Hu, "Determination of AKD sizing agents in papermaking systems by gas chromatography," World Pulp and Paper, vol. 31, no. 2, pp. 47-49, 2012. 

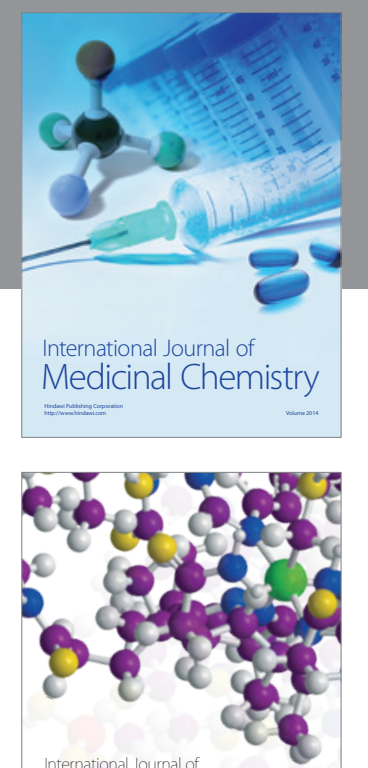

\section{Carbohydrate} Chemistry

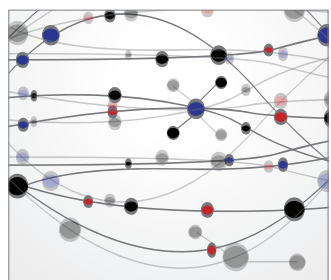

The Scientific World Journal
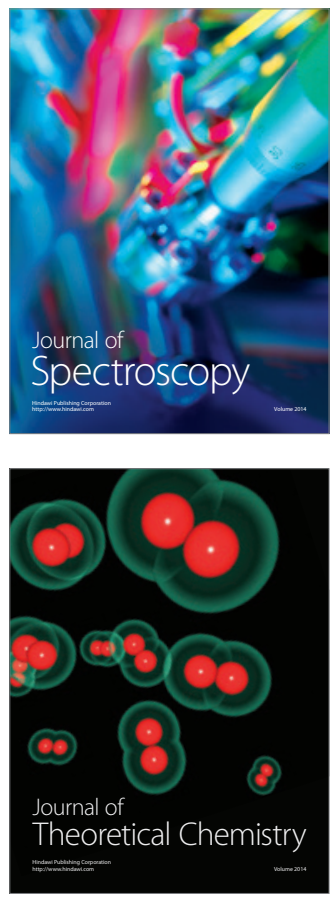
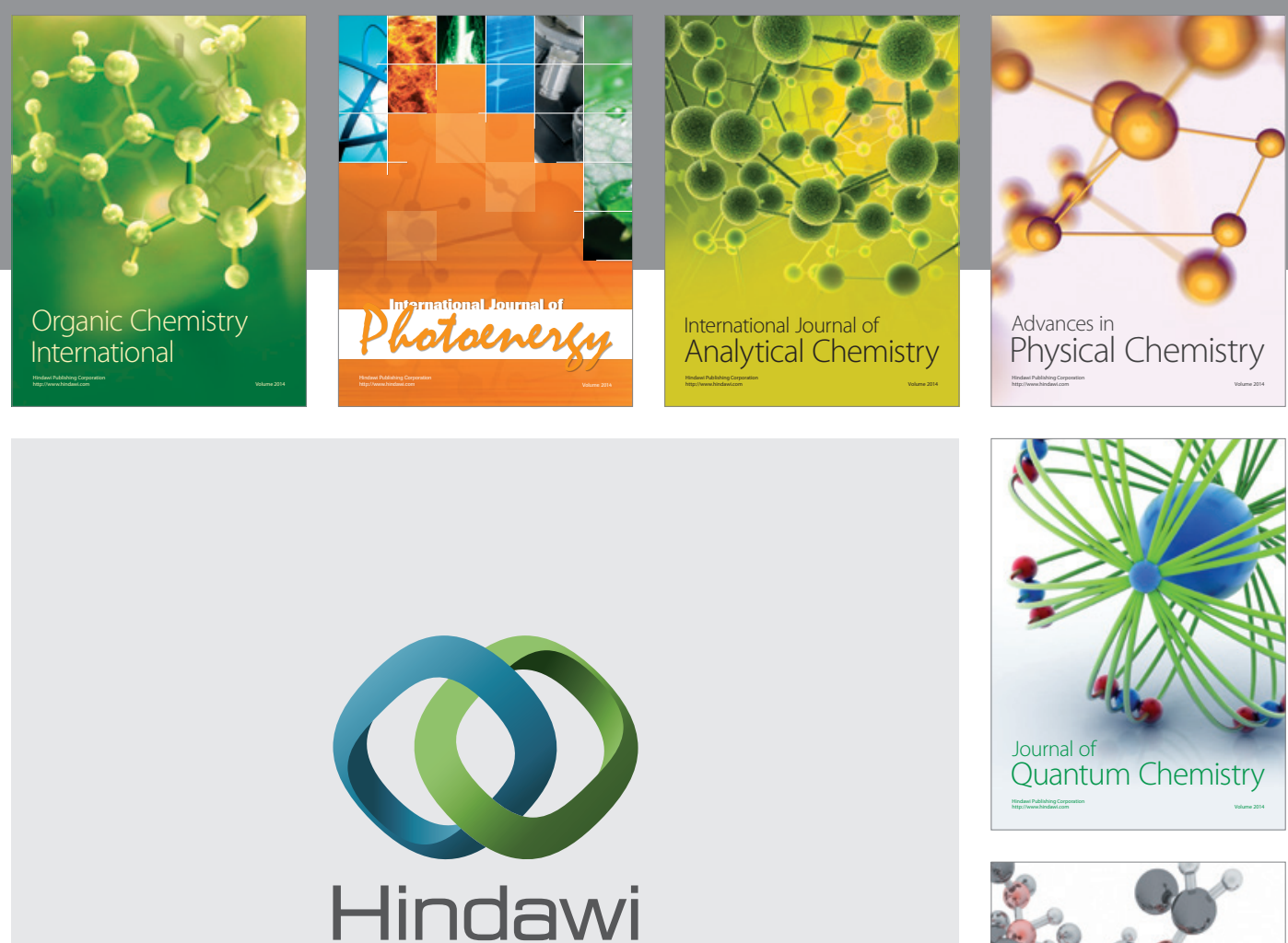

Submit your manuscripts at

http://www.hindawi.com

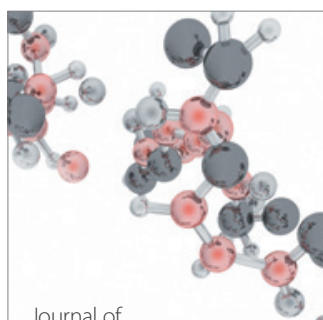

Analytical Methods

in Chemistry

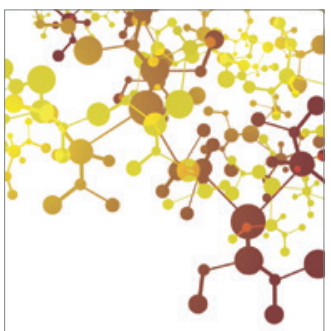

Journal of

Applied Chemistry

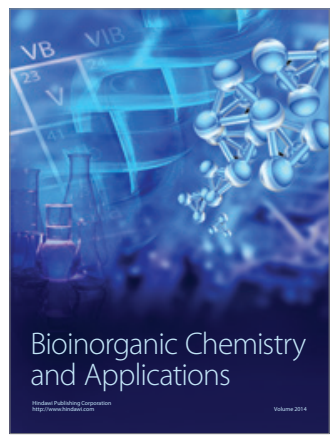

Inorganic Chemistry
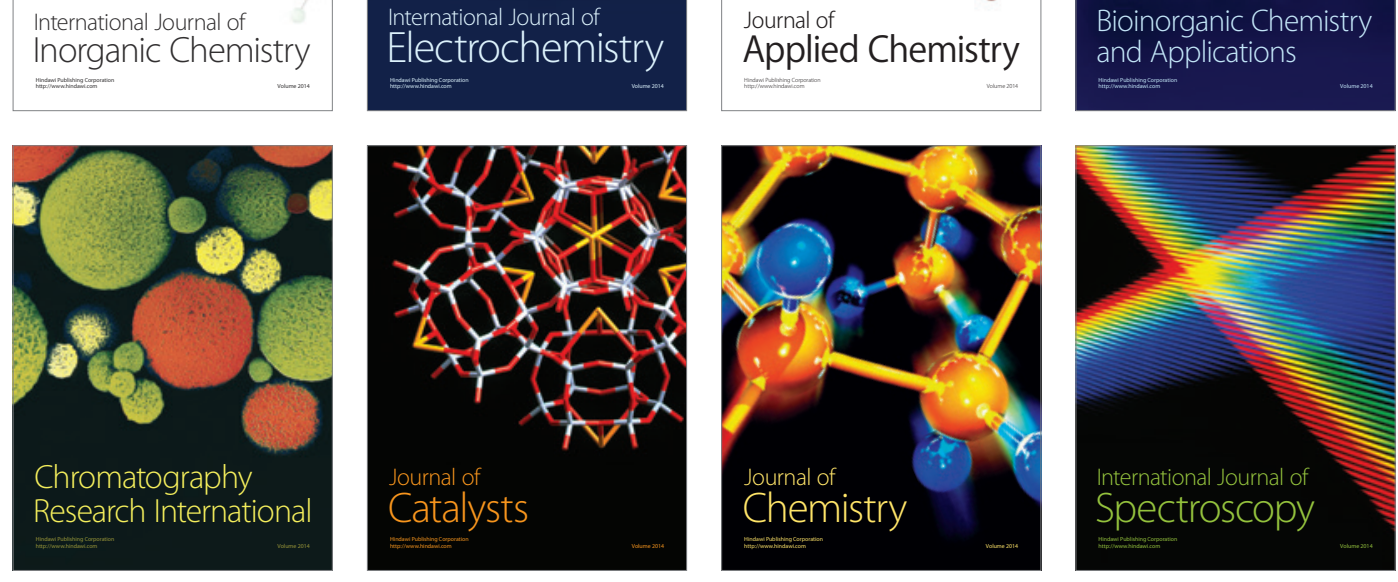